\title{
The illegal drugs market
}

Letizia Paoli

Max Planck Institute for Foreign \& International Criminal Law

\begin{abstract}
The article analyses the development and organization of the illegal drugs market in Italy. The first three sections of the paper reconstruct the evolution of drug use since the 1960s and discuss the key characteristics of illegal drug users, providing some estimates on their real number. The last three sections focus on the illegal drugs supply, identifying trends and constraints affecting the drug trade in Italy and the rest of Europe and assessing the involvement of southern Italian mafia associations in drug trafficking.
\end{abstract}

\section{Keywords}

Drug use, drugs markets, Italy, drug trafficking, mafia.

\section{Introduction}

Despite the lack of precise information, the drugs market is almost certainly the largest illicit market in existence in Italy today, both in terms of persons involved and of sales. Its expansion, in Italy as in all western countries, is relatively recent. Even though some of the narcotics prohibited today (opium, cocaine, and heroin) were already known and consumed by small segments of the population at the end of the 1800s, only starting in the late 1960s did the demand for derivatives of cannabis (marijuana and hashish, respectively the leaves and resin of the plant) and other drugs begin to expand enormously and become widespread among a consistent minority of younger generations. The first part of this essay reconstructs the sudden expansion of drug use. The second part discusses some of the characteristics of today's consumers of prohibited drugs. The third section presents the results of the most recent surveys regarding use of these substances. The final three chapters are dedicated to the market supply: the fourth analyzes trends and constraints regarding drug commerce throughout Europe; the fifth focuses on the involvement of mafia associations in southern Italy; and the sixth, final, chapter identifies the major characteristics of the drugs market and the businesses operating in this sector. 


\section{The evolution of drug use in Italy}

Until the mid-1960s, drug use in Italy was limited to a small circle of people belonging to an economic and cultural élite. Most of the population was not only extraneous to, but even ignorant of, the use of illegal drugs. As Marisa Rusconi and Guido Blumir (1972: 154) noted in the early 1970s, 'narcotics are a mysterious universe for the public. The newspapers are creating an image of Italian-style decadence.'

Only around the end of the 1970s did small groups of young people who were part of the collective movement of ' 68 and the hippie subculture imported from the USA begin to experiment with the mind-expanding properties of certain prohibited substances, in particular derivatives of cannabis and some types of hallucinogens. In these groups, which were based on friendship, musical tastes and common political ideas, the use of drugs was not obligatory. However, following a series of sensational campaigns in the press, drug use gradually became a way of defining group identity and reinforcing cohesion. In fact, the scandal provoked by the celebrated 'drug barge' incident in Rome and the news of 'drug parties' in numerous Italian cities contributed to a reputation of transgression for such groups, which in turn helped consolidate a sense of belonging for the members (Blumir 1976; Arlacchi and Lewis 1990b: 57-66; Ruggiero 1992: 135-48).

The research conducted by Luigi Cancrini (1977) and his associates in 1969-70 identified this first phase of the development of the Italian drugs market. Through an analysis of data collected in hospitals, prisons and high schools of the capital, the study showed that the consumption of illegal psychoactive substances constituted a very different and more limited phenomenon than that which was being reported in the press and on television. According to the Roman research group, at that time there were not more than 2,000-3,000 regular drug (primarily hashish and marijuana, but also hallucinogens and to a lesser extent, cocaine) users in all of Italy. The majority were young males of all social classes.

According to various scholars, the development of the market for heavy drugs during the 1970s originates not so much from the recent popularity of hashish and marijuana as from the broad diffusion of psychotropic drugs and, in particular, of amphetamines, which were sold freely until 1972. As Tullio Bandini and Uberto Gatti (1987: 293) note, "the mass diffusion of psychotropic drugs has created what we could call a "drug-phile" habit and has prepared the way for the diffusion of illegal drugs, in particular heroin'. Even before their prohibition, amphetamines were being used by small, counterculture youth groups in various Italian cities. Unlike cannabis consumers, these users tended to marginalize themselves from society and radicalize their contact with narcotics; they would break up and dissolve amphetamine tablets, normally taken orally, with the aim of injecting the drug and thus obtaining a more intense effect (Arlacchi and Lewis 1986, 1990b). 
At the same time that restrictions were placed on the sale of amphetamines, morphine in tablets or powder from Pakistan and Bangladesh started arriving in many Italian cities. The smuggling of this opiate derivative, which was rerouted from the considerable stock of morphine sent to these countries in the form of international aid, was not managed by a professionally organized distribution circuit. Most of it was transported to Europe by drug addicts coming from the East who had limited financial resources and were used to new forms of consumption (Arlacchi and Lewis 1986, 1990b).

Around 1973, heroin began to appear in the principal cities of the center and north and then progressively also in the smaller cities and the south. According to Blumir (1976), about 5,000 people in all of Italy were initially involved in the regular use of heroin; most were 'ex-amphetamine users, freak hooligans at the end of their rope' who repackaged themselves as dealers as soon as the prices began to rise. Heroin soon made converts among people disappointed by the outcome of the student protest movements and progressively also among middle- and lower-class youth, frequently the offspring of southern immigrants who had problems assimilating. In the space of a few years, this second component became dominant and heroin rapidly lost all its rebellious characteristics. As Pino Arlacchi and Roger Lewis (1990b: 77) note, already by the mid-1980s:

almost every trace of 'alternative' ideology from the early 1970s had disappeared. Even the image that developed immediately afterwards, that of the misunderstood young junkie who scrapes along in his own way and is at odds with an oppressive society lost almost all its appeal: the use of heroin had lost its transgressive status.

In the 1980s, with the diffusion of heroin among suburban youth, two parallel markets - one for heroin and the other for cannabis - were consolidated. Their places for trafficking and consumption always remained rigidly separated in that they were located in different, albeit not fixed, places in most Italian urban centers. With the passing of time, as had happened with heroin, even the consumption of cannabis derivatives lost its strict association with the post-1960s counterculture. Unlike heroin, however, hashish (marijuana became almost unobtainable and remained so until the mid-1990s) continued to attract new generations of young users from all social classes and education levels. While hallucinogens and amphetamines were already disappearing from nearly all Italian cities in the early 1980s, for all of that decade cocaine was enjoyed almost exclusively by members of two very distinct social groups: the underworld and the intellectual and political-economic élite of the country (Paoli 2000b).

In the 1990s, the polarization of the drugs market was undermined by the diffusion of new drugs. Some substances, such as ecstasy, were completely new. Others, such as cocaine, amphetamines and LSD were gradually rediscovered and/or became attractive to a relatively large number of users. 
From the late 1980s and the early 1990s, ecstasy, a meta-amphetamine with stimulating effects, started being taken by fans of techno and house music, and participants in raves, weekend-long musical events held outdoors or in industrial buildings. Paralleling the success of techno music, ecstasy pills soon became available in almost all the discotheques and clubs where young people went to dance (Bagozzi 1996, Parker et al. 1999) At the National Conference on Drugs held in Naples in 1997, the Minister of Social Affairs estimated (it is not known according to what criteria) that 85,000 youths between the ages of fifteen and twenty-five used ecstasy and other amphetamine products and hallucinogens (Piccone Stella 1999: 41).

At the end of the century, in Italy as in the rest of Europe, there was widespread use of cocaine, which had become a sort of passe-partout drug for a fairly differentiated spectrum of people (Bieleman et al. 1993; EMCDDA 2002: 13-14). The 'coke' of today is no longer snorted merely by an elite and affluent public, as was true in the 1980s; it is as popular among heroin addicts and former heroin injectors currently receiving substitute methadone treatment as it is among age groups usually associated with the consumption of ecstasy and cannabis derivatives. There is one substantial difference, however: those with previous experience with heroin tend as well to inject cocaine, while the 'kids' and 'disco-goers' snort it. In the late 1990s, crack also became available in the major northern Italian cities, even though it remained a niche product that appealed to people with previous experience in injecting heavy drugs (Paoli 2000b).

\section{Drug users today}

The multiplication of narcotics available corresponds to a diversification on the part of users. Drug users today can no longer be described by referring to just one set of social, demographic or cultural characteristics; nor can their use of drugs, which is often occasional or at least not compulsive, be traced to their supposed marginalization. In addition to 'traditional' drug addicts or 'junkies', drug users can be found in practically every social level and age group ranging from fifteen to twenty-five years of age. The 'paradox of normality' which, according to Patrizia Faccioli and Simonetta Simoni (1984) was already valid for heroin addicts in the mid-1980s, is even more valid today for users of other drugs. The majority are high-school or university students, office or freelance workers, or the unemployed: in other words, individuals who can hardly be distinguished from 'normal' people who do not take drugs.

In almost every Italian city, there is a hardcore of drug addicts for whom the use and procurement of drugs represent two of their most important daily activities. In Milan, for example, it is estimated that between 4,000 and 7,000 people regularly inject heavy drugs and obtain new supplies in the city squares. In Milan, as in all the principal northern and central cities, foreigners - and in particular the so-called 'extracomunitari' or those from outside the European 
Union (EU) - represent a new and increasing percentage of marginalized and addicted heavy drug users, offsetting completely or in part the decline of new users among the local population (Paoli 2000b).

Many immigrants, above all North Africans, are already used to smoking hashish or marijuana when they arrive in Italy. Once in Europe, however, some begin to consume the heavy drugs they are also involved in selling or in order to gather courage before committing thefts or robberies. Others experiment with narcotics so as to be accepted by their own communities or to forget their difficult living conditions and the unfulfilled dreams that caused them to emigrate. At the beginning of their drug-using careers, the 'extracomunitari' usually sniff or smoke cocaine or heroin, but once they become addicted, many begin injecting drugs, thus overcoming their own cultural barriers. As a Tunisian immigrant admitted during an interview in Milan in 2000, which was part of ethnographic research on the city market:

I really started in '94, just after arriving in Rome; at the time I used to steal from the supermarkets and department stores, and I started taking tablets, Roipnol and the like, and every once in a while I would smoke a joint. I started to drink some beer because I lived in an abandoned house with my friends, and for me taking drugs was a joke, everybody did it, we had fun and then once by chance I did heroin. It was really nice and from then on I haven't stopped: it's stronger than I am.

(Paoli 2000b: 89-90)

Neither in Milan nor elsewhere, however, are junkies the only users of prohibited psychoactive substances. Although they make up the most visible component, they are by no means the sole users. In fact, 'traditional' users of heroin and other heavy drugs constitute a minority. Various illegal substances imprimis hashish and marijuana, but increasingly also cocaine, ecstasy and synthetic drugs - are consumed by tens of thousands of teenagers and young (as well as not so young) adults from very different social classes and cultural milieux.

This new generation is encouraged to use drugs by today's mass youth culture, which spreads the same myths, values and expectations all over the world through songs, music, films and film stars. The positive and almost mythic image of many psychoactive substances, particularly the new 'fun drugs', is due to this supranational cultural movement. For many young people, these latest substances offer a way to feel part of a group, have fun, escape daily problems and eliminate anxieties and fears (Calafat et al. 1999). At the same time, the risks of narcotics use are underestimated. With the exception of heroin, these drugs are not considered to be dangerous, especially if they are used occasionally and in small doses. The perception of this new generation of drug users is that only those who shoot up are addicts (Calafat et al. 2001).

A common trend unites the various components of this increasingly diversified issue: over the last ten years there has been a notable normalization of drug 
use. In spite of their illegal status, the use of some psychoactive substances hashish above all, but in some contexts also cocaine and ecstasy - is considered 'normal' and is widely practiced and accepted. This tendency has been emphasized by many drug users interviewed in Milan for research done for the European Observatory on Drugs, known as the EMCDDA. For example, this is what a law student who regularly uses hashish claims:

especially in my city Milan, for the kind of people I hang out with and have always spent time with, it is really hard to find people who don't at least smoke a few joints. I don't have any friends who don't smoke hashish or pot, and some take ecstasy.

(Paoli 2000b: 86)

Another university student, who worked for years as a bouncer in a discotheque, echoes this statement: 'In the discos, drug use is so huge that if you work there it becomes normal to take drugs during the weekends' (Paoli 2000b: 82). This tendency towards normalization of narcotics use has also been noted by the municipal government and the local health services. In fact, the intervention guidelines jointly issued by the two offices in 2000 state:

We are witnessing the spread, both among youths and adults, of a culture of substantial normalization of drug use behavior: the collective symbolic system seems to accept the behaviors of use of some (legal and illegal) substances; only the heroin addicts are considered problematic and are criminalized and marginalized. This 'normalizing' culture deprives the very young of protective tools that can in some ways help them make sensible choices regarding their health: instead they are at increased risk of passing from occasional drug use to abuse and dependence.

(Comune di Milano 2000: 3; cf. Parker et al. 1999)

In other words, the use of certain drugs is no longer the expression of a rebellious counterculture, but has entered into and is part of the mass youth culture. Even though there can be negative consequences for some, drug use has in fact become a sort of rite of passage from adolescence to maturity for substantial segments of the youth population.

\section{The results of the first household and school surveys}

An evaluation of the dimensions of the illegal drugs market is rendered difficult not only by the multiform and multi-faceted nature of the question, but also by the illegal status of the goods. Everyone who participates in the narcotics trade imprimis the importers and distributors, but also the users - are, in fact, understandably interested in hiding as much as possible their own involvement, given the risk not only of moral and administrative sanctions but more often of heavy fines and prison sentences if they are found in possession of even minimal quantities of drugs. 
While in the last twenty years most industrialized nations have worked to overcome the difficulties of assessment due to the market's illegal nature, even today Italy has very few instruments at its disposal to evaluate the use of major drugs, the state and turnover of the market as a whole, and therefore the impact of anti-drug policies and activities. It is sufficient to note that Italy was for many years the only country in the EU that had never conducted research on a representative sample of the entire population regarding the use of the principal narcotic substances. The only survey of this sort was conducted for the first time in 2001 by the epidemiology section of the Institute of Clinical Physiology of the National Council for Research for the Department of Social Affairs of the Presidency of the Council (later merged with the Ministry of Labor and of Social Policy). Through the use of postal questionnaires, the researchers interviewed about 5,800 individuals representative of the adult (15-44 years) Italian population.

As shown in Table 1, 22 per cent of those interviewed, corresponding to about 5,400,000 people (of a total of 24,500,000 who are part of the above-mentioned age group; ISTAT 2003) admit to having had some experience with an illegal psychoactive substance during their lifetimes. For the overwhelming majority (21.9 per cent of the total), the substance was a derivative of cannabis. Less than 1 per cent (about 220,000 people) claimed to have used opiates, a percentage that almost doubles in the case of ecstasy (1.9 per cent, 440,000 people) and is slightly less for amphetamines and hallucinogens (in both cases 1.5 per cent, around 370,000 people). The percentage of those who have tried cocaine at least once in their lives is significantly higher: 3.4 per cent, corresponding to 830,000 people between the ages of fifteen and forty-four (Ministero del Lavoro 2002: 221-3).

For nearly all types of drugs, the highest use is registered among the segment of the population defined by the Italian Population Survey on Alcohol and Drug Abuse (IPSAD) as young adults - i.e. the 15,500,000 or so people between fifteen and thirty-four years of age. In this age category, the prevalence of the use of some sort of illegal substance is 24.7 per cent (around 3,999,000 individuals, an increase of 2.5 per cent over the previous survey); 24.5 per cent use cannabis products $(3,800,000$ individuals, an increase of 2.6 per cent), 4 per cent cocaine (630,000 individuals, a 0.6 per cent increase), and 2.6 per cent ecstasy (410,000 persons, a 0.8 per cent increase). Other figures remain unchanged: the use of opiates ( 1 per cent, an increase of 0.1 per cent over the previous sample), amphetamines (1.4 per cent, a decrease of 0.1 per cent) and hallucinogens (1.8 per cent, a 0.3 per cent increase compared with the entire adult population). These figures confirm the fact that some substances are less popular than others among younger generations and that their highest circulation peak was probably some years ago (Ministero del Lavoro 2002: 221-3).

A 2001 survey of more than 20,000 students in all years of high school (from 15 to 20 years old) produced values nearly identical to those of IPSAD for the use of cocaine and ecstasy (see Table 2). This survey, completed in the context 
Table I Prevalence of illegal narcotics use during one's lifetime

\begin{tabular}{|c|c|c|c|c|}
\hline & \multicolumn{2}{|c|}{ Adults (I5-44 yr) } & \multicolumn{2}{|c|}{ Young adults (15-34 yr) } \\
\hline & $\%$ & $n$ & $\%$ & $n$ \\
\hline Any illegal substance & 22.2 & $5,435,523$ & 24.7 & $3,879,|7|$ \\
\hline Cannabis derivatives & 21.9 & $5,362,070$ & 24.5 & $3,847,761$ \\
\hline Opiates (total) & 0.9 & 220,359 & I & $|57,05|$ \\
\hline Cocaine (total, including crack) & 3.4 & 832,467 & 4 & 628,206 \\
\hline Amphetamines & 1.5 & 367,265 & 1.4 & 219,872 \\
\hline Ecstasy & 1.8 & 440,718 & 2.6 & 408,334 \\
\hline Hallucinogens (total) & 1.5 & 367,265 & 1.8 & 282,693 \\
\hline
\end{tabular}

Source: Elaboration of IPSAD data.

Table 2 Prevalence (\%) of illegal narcotics use by high school students, 1999-200 I

\begin{tabular}{lccc}
\hline & ESPAD 1999 & ESPAD 2000 & ESPAD 200I \\
\hline Cannabis derivatives & 33.3 & 30.9 & 32.7 \\
Cocaine & 4.8 & 4.2 & 4.1 \\
Lsd & 3.4 & 2.7 & 2.2 \\
Amphetamines & 3.1 & 1.5 & 2.0 \\
Ecstasy & 3.1 & 4.2 & 2.0 \\
Heroin smoked & 3.1 & 4.2 & 2.0 \\
Hallucinogenic mushrooms & 1.6 & 1.4 & 1.4 \\
Heroin taken in ways other than smoked & 0.8 & 0.9 & 0.8 \\
Crack & 0.7 & 0.9 & 0.6 \\
\hline
\end{tabular}

Source: Ministero del Lavoro 2002: 218.

of ESPAD (European School Survey Project on Alcohol and Drugs), a project to gather data on the use and availability of drugs among fifteen- to sixteen-year-old students in thirty European countries, registered much higher percentages for the use of cannabis, however. In fact, a solid 33 per cent of those interviewed declared to have used hashish or marijuana at least once in their lives (Ministero del Lavoro 2002: 215-19). Even without reliable historical data, this figure seems to confirm the theory of the European Monitoring Centre on Drugs and Drug Addiction that in all countries of the EU during the 1990s, the use of cannabis increased, especially among youths (EMCDDA 2002: 13-14). The EMCDDA developed this hypothesis based on results of periodic surveys of other European nations. Since these investigations were never carried out in Italy before 1999, this trend can find confirmation in Italy only in the above-mentioned margin and in the results of ethnographic research such as that carried out by the author in Milan (Paoli 2000b). The slight decline in the number of youths who admitted to using cannabis in the ESPAD surveys conducted in Italy between 1999 and 2001 (from 33.3 per cent in 1999 to 32.7 
per cent in 2001, with a minimum of 30.9 per cent in 2000) can be taken as confirmation of a corollary of the above-mentioned thesis of the EMCDDA: after a period of sustained growth, the use of hashish and marijuana is finally stabilizing (EMCDDA 2002: 13-14).

While the rates of lifetime prevalence inform us about the number of people who have had even remote experiences with drugs, the data regarding use of narcotics in the twelve months and in the thirty days previous to the interview are much more precise about the actual state of the market. As can be seen in Tables 3 and 4, for all drugs these figures are significantly much lower than those for drug use in the course of one's lifetime. At the same time, the gap increases between the percentages verified for the adult population (15-44 years) and those applying only to the youth segment (15-34 years). In fact, 6.4 per cent of the first group (more than 1,500,000 people) admit to having used some type of illegal substance during the previous twelve months, while for young adults the percentage rises to 9.4 per cent. The projections on the entire population make

Table 3 Prevalence of use of illegal substances in the past year

\begin{tabular}{|c|c|c|c|c|}
\hline & \multicolumn{2}{|c|}{ Adults (15-44 yr) } & \multicolumn{2}{|c|}{ Young adults (I5-34 yr) } \\
\hline & $\%$ & $n$ & $\%$ & $n$ \\
\hline Any illegal substance & 6.4 & $\mathrm{I}, 566,998$ & 9.4 & $\mathrm{I}, 476,284$ \\
\hline Cannabis derivatives & 6.2 & $1,518,029$ & 9.2 & $\mathrm{I}, 444,873$ \\
\hline Opiates (total) & 0.5 & 122,422 & 0.6 & 94,231 \\
\hline Cocaine (total, including crack) & I.I & 269,328 & 1.7 & 266,987 \\
\hline Amphetamines & 0.1 & 24,484 & 0.1 & 15,705 \\
\hline Ecstasy & 0.2 & 48,969 & 0.3 & 47,115 \\
\hline Hallucinogens (total) & 0.2 & 48,969 & 0.2 & 31,410 \\
\hline
\end{tabular}

Source: Elaboration of IPSAD data.

Table 4 Prevalence of use of illegal substances in the past month

\begin{tabular}{|c|c|c|c|c|}
\hline & \multicolumn{2}{|c|}{ Adults (I 5-44 yr) } & \multicolumn{2}{|c|}{ Young adults (15-34 yr) } \\
\hline & $\%$ & $n$ & $\%$ & $n$ \\
\hline Any illegal substance & 4.6 & $\mathrm{I}, 126,280$ & 6.9 & $1,083,655$ \\
\hline Cannabis derivatives & 4.4 & $1,077,311$ & 6.6 & $1,036,540$ \\
\hline Opiates (total) & 0.2 & 48,969 & 0.2 & 31,410 \\
\hline Cocaine (total, including crack) & 0.7 & $17 \mid, 390$ & 1.1 & 172,757 \\
\hline Amphetamines & - & - & - & - \\
\hline Ecstasy & 0.2 & 48,969 & 0.2 & 31,410 \\
\hline Hallucinogens (total) & 0.2 & 48,969 & 0.2 & 31,410 \\
\hline
\end{tabular}

Source: Elaboration of IPSAD data. 
even clearer the fact that recent use of prohibited substances is concentrated in the younger segments of the Italian population: more than 94 per cent of the $1,570,000$ individuals who admit to drug use in the last year are between fifteen and thirty-four years of age. As with lifetime prevalence, the statistics pertaining to the previous year's use reveal that cannabis is by far the most popular illegal psychoactive substance: 9.2 per cent of young adults admit to having tried it at least once. The second most popular substance is cocaine, used by 1.7 per cent of young adults, followed at a distance by opiates ( 0.6 per cent of young adults), ecstasy (0.3 per cent), hallucinogens and amphetamines (0.2 and 0.1 per cent respectively) (Ministero del Lavoro 2002: 221-3).

Just over one million adults admit to having smoked a derivative of cannabis in the thirty days previous to the interview, the equivalent of 4.4 per cent of the Italian population between the ages of fifteen and forty-four. Among young adults, the same index is of 6.6 per cent. The figures are much lower for other drugs: 170,000 people claim to have used cocaine, and just under 50,000 opiates, ecstasy and hallucinogens. For all substances, the figures are higher for young adults (Ministero del Lavoro 2002: 221-3).

It is worth noting, however, that, given the smallness of the total sample and, within this, of current users of all drugs other than cannabis, the percentage values are intended more as general indications than as reliable assessments. Problematic drug users in particular are hard to reach through postal questionnaires such as those used by IPSAD, since they tend to live in precarious or irregular situations and do not necessarily answer correspondence on a regular basis. Not by chance, the estimates developed by the Ministries of the Interior and of Health in the second half of the 1990s for the number of serious drug addicts are much higher than the projections based on the data of the first sample survey of the adult Italian population. According to these estimates, the number of drug addicts who, for the most part, inject heroin (and at times inject or consume other drugs) is placed at around 250,000 (OIDT 2003: 20).

Even though the 'traditional' use of heroin is considered by most Italian and European experts to be stable or in decline (EMCDDA 2002: 15-19), until 2002, OIDT (the Italian Observatory for the Verification of the State of the Phenomenon of Drugs and Drug Addiction) presented increasing estimates of the number of Italian drug addicts (OIDT 2002: 7). Given the poor quality of the data on which such evaluations are founded, it is not possible to ascertain with certainty if the increase in the official data is the result of an actual rise in the problematic consumption of heroin or of refined research methods. In reality, heroin abuse does not seem to be on the rise, judging from the patterns of the heroin addicts and poly-drug users who are clients of public drug-treatment centers (Servizi per le Tossicodipendenze, usually known as Ser. T) and private detoxification centers, as well as the aging of the subjects and the substantial reduction of deaths by overdose. ${ }^{1}$

What is clear is that the number of people who shoot up heroin and other heavy drugs in Italy is higher than the European average. In fact, EMCDDA 
estimates that in Italy there are six to seven problematic drug users (mostly heroin addicts and poly-drug users) for every 1,000 citizens between fifteen and sixty-four years of age. This is higher than most European countries, where values range from 2.6 per cent in Holland and 5.9 per cent in Ireland. Within the EU, only the UK, Portugal and Luxembourg have higher values: 6.9, 7.3 and 9.9 per cent respectively (EMCDDA 2003: 19).

If the figure regarding heroin addicts is higher than the European average, Italy - despite the absence of regular surveys and the difficulties of comparison between research conducted with non-homogeneous methodologies and samples - seems to register figures lower than other European countries for the use of other drugs, in particular of cannabis and amphetamines (EMCDDA 2002: 12, 17-18). While in certain European countries such as Denmark, France, the UK and the Netherlands, more than 35 per cent of adolescents and young adults interviewed claim to have experience with cannabis derivatives, in Italy the figures vary, depending on the survey, from 24.7 per cent in the IPSAD study to 17.2 per cent in the European Opinion Research Group's recent survey of EU citizens from fifteen to twenty-four years of age. The European average arrived at through this study is 28.8 per cent. Not only the 'prevalence during lifetime' figure but also the 'current use' figure thus is lower in Italy than in other EU countries: in fact, according to these research figures, 'only' 7.8 per cent of Italians interviewed declared to have used cannabis during the month before the interview, while 0.8 per cent admitted to having used other drugs. At the European level, the monthly figures are respectively 11.3 per cent for cannabis and 2.7 per cent for other substances (EORG 2002: 6).

\section{Drug traffic: trends and constraints common to all of Europe}

Starting in the early 1970s, pre-existing criminal organizations - in Italy, primarily mafia groups of the South - and innumerable other players, attracted by large potential profits, became involved in the business of satisfying the increasing demand for drugs. While at the end of the 1960s most substances sold in western Europe were imported in small quantities by the users themselves (the so-called 'traffic of ants') (Cancrini 1977; Arlacchi and Lewis 1986, 1990b: 57-66; Ruggiero 1992: 149ff.), in the following decades a great number of businesses sprung up to handle the importation from cultivation and production zones as well as distribution in consumer countries.

The development of the drugs market caused the decline all over Europe of the underworld: the microcosm of thieves, robbers, pimps, gamblers and those dealing in stolen goods. In the last thirty years, a whole array of professional criminals has joined the distribution chains of heavy drugs in the anonymous and interchangeable roles of traffickers, pushers and mediators. During an inquiry into the drugs market in Turin, an informer recounted the following to Vincenzo Ruggiero: 'I have always hung around with lots of robbers, and I can 
say that 90 per cent of the ones I know have gone from robbery to pushing drugs' (Ruggiero 1992: 196; see also Paoli 2000b: 106-7; Hobbs 1995).

Despite the singularity of Italian mafia associations (see Paoli 2003) and their involvement in drug traffic, this activity seems to function in Italy along the same lines as in the rest of western Europe. ${ }^{2}$ In all countries with a relatively efficient state apparatus, in fact, whoever is involved in the drug trade or other illegal goods and services is subject to the same constraints resulting from the illegality of the goods exchanged: in other words, it is necessary to operate (1) 'without' and (2) 'against' the state (Paoli 2002).

Since the goods and services provided are prohibited, the illegal market players cannot appeal to public institutions in order to guarantee that contracts are respected and eventual violations sanctioned. Nor does there exist in the illegal arena an alternative power center to the state to whom the contracting parties may turn in order to obtain reparations of a wrong. The illicit markets are characterized by the absence of a formal legal system: thus they lack a coherent body of rules upheld by sanctions and an enforcement apparatus run by an authority super partes to guarantee that terms of transactions be respected (Reuter 1985; Arlacchi 1988). Consequently, property rights are far from certain, work contracts cannot be formalized, and the development of large businesses with formal organizational structures and a high degree of stability are strongly discouraged.

All the players in illegal markets are forced to operate under the constant threat of arrest and confiscation of property by state agents. This is the consequence of doing business 'on the wrong side of the law', since the products they deal in are tout court prohibited or at least subject to heavy restrictions. Certainly, the actual risk of arrest and seizure of property varies according to the context and the opposition. If illegal entrepreneurs are particularly skilled in corrupting the representatives of state institutions, or if state representatives are weak and inefficient, the risk is greatly reduced. In most European countries, however, the risk cannot be eliminated completely. In varying degrees all illegal entrepreneurs must factor in such risks and take appropriate precautions to avoid arrest and confiscation of property.

To this end, illegal entrepreneurs usually turn to collaborators and partners who are connected to them through natural or artificial family relations - the primary advantage of the mafia fraternities in southern Italy - or at least through common origins, language or religion. Thus the logic of security tends to prevail over that of competence and profitability (Becchi and Rey 1994).

Furthermore, whoever does business in prohibited goods will attempt to organize his activities, especially those that involve other partners, in such a way as to minimize the risk of intervention on the part of opposing authorities. In particular, each entrepreneur will aim to structure his relations with partners and clients in such a way as to limit their information about his role. An efficient strategy is segmentation of the business, which reduces the number of people in contact with the entrepreneur. In this way only a few individuals have direct and 
first-hand knowledge regarding his involvement in illegal traffic: the aim is to minimize the probability of an involuntary dissemination of information and hence reduce the entrepreneur's vulnerability to the state.

For the same reasons, opportunities for vertical integration are destined to remain limited. Illegal businesses have very few incentives to expand either up or down - i.e. to internalize phases of the production cycle that come before or after their own. Regardless of the direction, the internalization of a function implies added risks of interception by law enforcement and increased costs related to the management of a larger and differentiated workforce. These costs, in particular, tend to increase rapidly. In fact, it is quite difficult to control the performance of workers who, given the nature of the business, must operate under clandestine conditions and seek to minimize the production of written documents that could become proof of their illegal activities. Rather than expand, illicit businesses therefore tend to purchase on the market most of the services they need.

Because of the constant threat of police intervention, the temporal horizon of criminal ventures tends to be shorter than that of their legal counterparts; and, since an illegal venture cannot be sold, as the owner becomes older he will most likely invest an increasing portion of his earnings in legal properties so as to be able to transmit them to his heirs (Reuter 1985; Paoli 2002).

For all these reasons, the drugs markets in the western world tend to be populated by small, and not highly institutionalized, enterprises: the factors that promote the development of large companies in the legitimate sphere - economies of scale and the specialization of roles - are counterbalanced in the illicit sphere by the consequences of the illegal status of the commodities. Such products instead favor small and flexible entrepreneurial structures that can more easily evade interception by law enforcement agencies.

\section{Mafia associations and drug traffic}

Even the mafia associations in southern Italy are subject to constraints resulting from the illegal nature of the goods. Hence, when they deal in narcotics or other illicit goods, they operate in small teams or allow a free hand to their members. The great transcontinental traffic of heroin, as was reconstructed in the first Palermo 'maxi-trial', is emblematic of this mode of operation. One often reads in the media that the entire business was dominated by the Sicilian group Cosa Nostra (for more information on Italy's most dangerous and famous mafia association, see Paoli 2003). A precise reading of the judicial acts reveals, however, that the various phases were managed by members of different mafia families who, rather than considering themselves part of the same economic unity, jealously guarded their own networks of clients and suppliers as well as their specializations. About this point the investigating judges of the first anti-mafia pool wrote: 
in essence, therefore, within Cosa Nostra autonomous yet functionally linked structures were created, which were responsible for the various phases of articulation of the complex narcotics trafficking, while the 'men of honor, ${ }^{\text {, } 3]}$ who do not have operative responsibilities, can contribute financially, thus sharing in varying degrees, the profits and risks.

(TrPA 1985: 1887)

Cosa Nostra facilitated the development and consolidation of exchanges by creating a climate of trust and belonging. Only with difficulty, however, can these relationships be compared to operative relations among different sections of the same business: instead, they were more like transactions among businesses so distinct from one another that, despite the trust of the mafia brotherhood, the respect of contracts was guaranteed by every means, including threats and use of violence.

The import of considerable quantities of morphine was directed by Nunzio La Mattina, a former Kalsa smuggler who had been adopted by Pippo Calò into the Porta Nuova family because of his contacts with illicit international markets. Later he was joined by Antonio Rotolo, Tommaso Spadaro and Giuseppe Savoca, who, however, 'each worked on their own and jealously guarded the secret of their own organizations'. According to the Palermo magistrates, in two years La Mattina and Rotolo imported to Sicily at least two tons of morphine, a value of more than $\$ 55,000,000$ (TrPA 1985: 1879-80).

Other people were responsible for transforming morphine into heroin in clandestine laboratories, operating partly on their own and partly for third parties: according to the mafia defector Salvatore Contorno, at the beginning of the 1980s there were at least seven such laboratories in western Sicily, each of which was managed by a Cosa Nostra $\cos c a^{4}$ or by a group of 'men of honor'. Francesco Marino Mannoia, who was highly sought after for his skills in chemistry, recalls having worked in numerous labs, refining morphine that belonged to various affiliated companies. Finally, there were those responsible for the shipment of the finished product and the wholesale distribution in the USA. Prominent roles were played in this area by the Bontade, Inzerillo and Badalamenti groups, whose blood and mafia families had ample networks throughout North America. Heroin was packaged in cellophane packets, on which were affixed conventional symbols to distinguish the various owners, each of whom was responsible for the quality of his lot. According to Tommaso Buscetta, the liberty of the individual investors was such that they could collect their lot of the finished product in Sicily and make their own arrangements for the sale of the drug (TrPA 1985: vol. 9).

Far from being stable and centralized entities, many of the illicit businesses established by the 'men of honor' for drug trafficking resemble what anthropologists call 'action sets': temporary coalitions formed to achieve specific goals which disperse once those goals are reached (Blok 1988: 136ff.). At times it is the cosca that manages the entire illicit deal; much more often, however, its 
supporters constitute illegal businesses that are quite distinct from their mafia group because of their heterogeneous composition, short lifespan and financial and managerial independence (see Paoli 2000a: 197-203).

Thus, all the other operators in the drugs market, the enterprises managed by members of mafia families, are subject not only to the constraints deriving from product illegality but also to the laws of economic competition. It is precisely for this reason that, with the exception of the Cuntrera-Caruana group, the groups of Cosa Nostra have been marginalized from the major transcontinental traffic in heroin and cocaine for more than a decade, even though single 'men of honor', either alone or in partnership with others, may still be importing and dealing in narcotics. Numerous factors have impeded Cosa Nostra families from maintaining the market positions they held in the early 1980s. Among these factors must be weighed the successes of American and Italian law enforcement, which have been exercising a pressing and effective counteraction through operations such as 'Pizza Connection' and 'Iron Tower' (Jacobs et al. 1994: 129-66). A decisive element was represented by the outcomes of the second 'mafia war' in Sicily: the winning side - the so-called Corleonese coalition succeeded only in part in taking over the extensive drug cartel built by the losing families who had benefited from extensive networks in the USA. Since the mid-1980s, the families in the innermost nucleus of the Corleonese coalition seem to have made a predominant part of their proceeds from the manipulation of major public works contracts in Sicily, while neglecting the traffic of narcotics (Ministero dell'Interno 2001; Paoli 2000a, 2003: 215-17).

The marginalization of the Sicilian families from the refinement and trade of large quantities of heroin destined for the US market is part of a long-standing pattern that now appears clear: the progressive concentration of the process of refinement in the same place as the cultivation. As in other markets, the refinement of the finished product (heroin) and the semi-finished products (morphine and base heroin) is now carried out much more frequently in developing countries where the production and labor costs are significantly lower.

The Cosa Nostra groups are also at a disadvantage because of their peripheral location, which keeps them far from not only the areas of narcotics production but also, and above all, the final market centers in Europe and the USA. Most of the heroin distributed in the European markets today is imported from a multitude of Turkish, Kurdish and, more recently, Albanian family businesses that are located at the hub of transportation routes, can hide themselves in Europe-wide ethnic diasporas, or benefit from the weakness of their governments (Paoli 2000b). Likewise, the numerous Colombian clans who refine more than 70 per cent of the cocaine for export also handle transport to Europe or at least sell their goods to multiple intermediaries, both big and small. Contrary to more pessimistic predictions, Cosa Nostra does not in the least have exclusive rights. In fact, the seizures and investigations of the last ten years show that the preferred countries for the entry of cocaine into Europe are Spain, where the 
Colombian dealers have the advantage of the language and the presence of a growing community of compatriots, and Holland, whose commercial ports, the busiest in Europe, provide opportunities for the clandestine import of drugs (EMCDDA 1998: 36-7, 2001: 21).

Thanks to their more extensive networks in the center and north of Italy as well as in various European countries, the families of the Calabrian 'Ndrangheta ${ }^{5}$ managed, at least until the middle of the 1990s, to maintain their position in the international cocaine market, as is demonstrated by the seizure of more than 5,000 kilograms in 1994. These families operate primarily as wholesale distributors on the domestic heroin and hashish markets, although they also occasionally import considerable shipments of these substances (PrMI 1997; TrMI 1997). Today, however, even the Calabrian mafia groups are greatly weakened by investigations that have thrown their settlements in central and northern Italy into disorder, and now they must cope with competition from new, agile and mutable criminal associations at all levels of the narcotics distribution system (Paoli 2000b).

\section{Open markets, small businesses}

In Italy, as in the rest of Europe, most drug exchanges today, even those of considerable quantities, seem to be carried out by numerous businesses, most of which are small and often ephemeral. Some of these are family-run 'companies' managed by blood family members who may call on extraneous individuals for more dangerous services. Others are actual groups that take shape around a charismatic leader, acquire a minimum of temporal stability and develop a division, albeit rudimentary, of labor. Still others are teams: loose groups of three, five, perhaps ten people that form, disperse and reunite according to opportunity. These three typologies describe the businesses run by 'men of honor', mafia and pseudo-mafia groups in southern Italy, as well as those established by foreign criminals who operate at higher levels in the distribution system. Members of local underworlds in nearly all the cities of central and northern Italy are presumably also organized in groups or teams (Paoli 2000b, 2003).

Many dealers, above all at intermediate and lower levels, work alone, both in order to finance their own habit and, more rarely, to accumulate money quickly. Most of these 'entrepreneurs' have no contact with the underworld: they are usually people above suspicion who are difficult to distinguish from 'respectable' citizens. As one of the people we interviewed, a regular cocaine user, notes: 'My suppliers are all Italians from Milan ... they are for the most part normal people who push drugs to round out their incomes.' Another young Milanese describes his hashish pusher in this way: 'He is - it sounds a bit ridiculous to say he's a drug dealer - a serious person, he's not a kid or a hothead, he works, uses his head, has a girlfriend, two dogs, goes to the gym a lot; he's a normal person just like me: I smoke and he deals' (Paoli 2000b: 115; see also Gruppo Abele 2003).

Most of these 'normal' subjects are active in the medium to low ranges of the 
distribution system. Some of them, however, often with the help of a few trusted collaborators, are able to manage considerable lots and even to import drugs directly from the countries of production. It should suffice to say that Pasquale Centore from Campania, one of the biggest cocaine traffickers in Milan, was for years a bank employee. Even though he was not part of the camorra or any other criminal organization, in the mid-1990s he was able to import numerous drug lots from Latin America in quantities that ranged from 400 to 700 kilograms (PrMI 2000).

In the principal urban centers of Italy as in most European cities, the street market is dominated by foreign pushers who operate in small groups or work as 'horses' for wholesale distributors - i.e. they pay for the drugs after having sold them. As the criminal statistics as well as the interviews with law enforcement officers, users and sellers of drugs show, in the early 1990s an actual process of substitution began: the lowest and most dangerous roles, which previously were performed by the most marginalized native addicts, now began to be filled by foreigners, in particular recent immigrants who had requested political asylum or were without residency permits. 'Ten years ago,' one former seller of cocaine and hashish in Milan claims, 'the dealers were mostly Italians, but today they are mostly foreigners' (Paoli 2000b: 112; see also Colombo 1998). The impressions of this interviewee are confirmed by statistical data: between 1990 and 1999 the percentage weight of foreigners on the total of those convicted for drug-related crimes rose from 10.2 per cent to 31.9 per cent (see Table 5).

As with other, older forms of crime, the buying and selling of drugs constitutes an alternative social mobility route for some immigrants. In greater measure than in the past, immigrants now encounter serious obstacles in accessing the legal economy and, owing to the restrictive policies adopted by most western countries, are forced to look for ways to survive in the informal or even criminal economy. Moreover, many recent immigrants use drugs themselves and have started dealing in order to support their own habit. The story of Kuku, a Senegalese who for several years has been selling cocaine and crack in Milan, is emblematic:

I've been dealing since '97, but first I handed out advertisements, it was really hard work, they paid me by how many pamphlets I distributed, I had to carry them door to door and I had trouble getting people to open the door to me, it was a mess. After a while someone from my country took me to the Chinese stores in Via Sarpi and Piazza Lima, where you find wholesale all the goods you need for street vending, and I started doing vù cumprà (do you want to buy?), as you call it, but I never managed to make enough money and I was tired of hearing people speak ill of me, sometimes even insulting me, and of always living with twenty people in a one-room apartment. I started dealing when I met some Nigerians who offered to give me some cocaine on credit and to pay them for it once I'd sold it. I accepted because I didn't have any money and I had to pay my share for my place to sleep, and 
Table 5 Convictions for drug-related crimes, 1990-1999

\begin{tabular}{llll}
\hline Year & Convicted for drugs & No. foreigners & \% foreigners \\
\hline 1990 & 7,852 & 799 & 10.2 \\
1991 & 13,139 & 1,276 & 9.7 \\
1992 & 14,810 & 2,338 & 15.8 \\
1993 & 13,402 & 3,174 & 23.7 \\
1994 & 11,945 & 3,550 & 29.7 \\
1995 & 12,197 & 4,132 & 33.9 \\
1996 & 20,227 & 5,977 & 29.5 \\
1997 & 19,622 & 4,920 & 25.1 \\
1998 & 20,715 & 6,278 & 30.3 \\
1999 & 18,134 & 5,785 & 31.9 \\
\hline
\end{tabular}

Source: ISTAT, Judicial and Penal Statistics, various years.

it went well and I kept doing it ... you shouldn't think bad of me, you know what it's like to live here. In this country they taught me that I have to get by on my own. Here social services and relief for the unemployed don't exist, it's not like in Belgium, and what's more there are lots of racists who don't give work to colored people and I spent two hellish years with these racists.

(Paoli 2000b: 113)

For various periods in the 1980s and early 1990s, some of the mafia and underworld groups imposed systems of monopoly not only in their own traditional communities but also on some neighborhoods of central and northern Italian cities, including Milan and Turin, requiring local dealers to buy from their suppliers (Ruggiero 1992; Paoli 2000b). In spite of this, no individual or group has ever succeeded in controlling the entire city market for one or more illegal substances, in part because every urban center is supplied through multiple, independent channels. With the exception of a few mafia strongholds in southern Calabria and western Sicily, the Italian drugs markets have always been open, in which everyone is free to try their fortune selling, importing or manufacturing drugs.

Even if further studies are necessary, the empirical research already carried out in individual urban contests shows that in Milan, Turin,Verona, Bologna and Rome - and presumably in the other Italian cities as well - the relationship among the businesses operating on the drugs market are closer to competition than collusion (Arlacchi and Lewis 1986, 1990a, 1990b; Ruggiero 1992; Paoli 2000b; Gruppo Abele 2003; see also Becchi 1996). Although some suppliers may enjoy a considerable monopolistic power in some, albeit limited, sectors of the market (Paoli 2000b: 108-9), the overwhelming majority are price-takers instead of price-givers: they are not able to influence the price of goods by varying the quantity they place on the market. Not by chance, in Italy, as in the rest of western Europe, the prices of the principal illegal psychoactive substances 
- with the exception of cannabis - have dropped over the last thirty years. Despite the profuse efforts on the part of law enforcement agencies in the war against drug traffic, this fact says a great deal about the effectiveness of the anti-drug policies aimed at curbing availability.

\section{Notes}

I In most regions of Italy, the number of clients of public drug-treatment centers (Ser. $\mathrm{T}$ ) continues to increase, but at a much slower pace than that registered in the early 1990s when Ser. Ts accommodation capacity was greatly expanding. In 2001, for example, Ser. T centers served more than 150,000 individuals, an increase of 2.2 per cent over the previous year. During the 1990s, however, there was a steady decrease in the number of Ser. T clients willing to undergo treatment in private detoxification centers, whose services are calibrated for 'old-style' heroin addicts: in 1991 the private centers attracted 22.3 per cent of Ser. T clients, while in 2001 the percentage value was 12.9 per cent. The consolidation of heroin use is also shown indirectly by the data regarding the principal substance abused by Ser. T clients: while in 1992 heroin was the main drug of abuse for 91.2 per cent of clients, in 2001 'only' 81.4 per cent of known users were heroin addicts. During the 1990s there was also a distinct aging of individuals in public treatment centers, which mostly work with those injecting heavy drugs, primarily heroin. In 1991, the average age of male clients contacted for the first time was 26.1 years and was 28.5 years for those already under treatment. Ten years later, the relative ages were 29.1 years and 32.4 years (Ministero della Salute 2002). Beginning in the mid-1990s, deaths from overdose, primarily of heroin, also strongly diminished; in 1996, 1,566 deaths were registered, and only 822 in 2001 (48 per cent) (DCSA 2002: 59).

2 Cosa Nostra in Sicily and the 'Ndrangheta in Calabria are Italy's largest and most stable mafia associations and are each composed of about a hundred mafia groups or families, as they are called by their members. With their centuries-old histories, articulated structures, sophisticated ritual and symbolic apparatuses and claim to exercise a political dominion, these associations have few parallels in the world of organized crime. With varying degrees of justification, other groups and networks are also routinely termed as 'mafia' or organized crime: these range from the Neapolitan camorra to Apulian organized crime and the so-called new 'foreign mafie' and other criminal entrepreneurs (see Paoli 2003, 2004).

3 'Men of honor' is the expression used by Cosa Nostra 'made' members to define themselves: on the meaning of this expression, see Paoli (2003: 65-75).

4 Ever since the nineteenth century, the word cosca, which means 'artichoke' in Sicilian dialect, has been employed by external observers and increasingly by mafia members themselves to refer to mafia groupings.

5 The 'Ndrangheta is currently Italy's largest and most powerful mafia association. Listing over five thousand ritually affiliated members, the 'Ndrangheta is larger than Cosa Nostra, whose 'made' members are estimated at 3,500 units. Owing to the greater relevance of blood family ties, the 'Ndrangheta has been less hit than the Cosa Nostra by law enforcement repression during the 1990s (for more information, see Paoli 2003). 


\section{References}

Arlacchi, Pino (1988) 'Saggio sui mercati illegali', Rassegna italiana di sociologia 29(3): 403-36.

Arlacchi, Pino and Lewis, Roger (1986) 'Analisi del mercato delle droghe pesanti e sua influenza ai fini della determinazione della categoria giuridica della modica quantità', Rome: Commune di Roma.

— (1990a) 'Droga e criminalità a Bologna', Micromega 4: 183-221.

- (1990b) Imprenditorialità illecita e droga. Il mercato dell'eroina a Verona, Bologna: Il Mulino.

Bagozzi, Fabrizia (1996) Generazione in ecstasy, Turin: Gruppo Abele.

Bandini, Tullio and Gatti, Uberto (1987) Delinquenza giovanile. Analisi di un processo di stigmatizzazione e di esclusione, Milan: Giuffrè.

Becchi, Ada (1996) 'Italy: Mafia-dominated drug market?', in Nicholas Dorn, Jørgen Jepsen and Ernesto Savona (eds) European Drug Policies and Enforcement, London: Routledge, pp. 119-30.

Becchi, Ada and Rey, Guido (1994) L'economia criminale, Bari, Rome: Laterza.

Bielemann, B., Díaz, A., Merlo, G. and Kaplan, Ch. D. (eds) (1993) Lines Across Europe. Nature and Extent of Cocaine Use in Barcelona, Rotterdam and Turin, Amsterdam: Swets \& Zeitlinger.

Blok, Anton (1988) The Mafia of a Sicilian Village, 1860-1960: A Study of Violent Peasant Entrepreneurs, New York and Oxford: Polity Press.

Blumir, Guido (1976) Eroina, Milan: Feltrinelli.

Calafat, Amador, Bohrn, Karl, Juan, Monserrat, Kokkevi, Anna, Maalsté, Nicole, Mendes, Fernando, Palmer, Alfonso, Sherlock, Kellie, Simon, Joseph, Stocco, Paolo, Sureda, M. Pau, Tossmann, Peter, van de Wijngaart, Goof and Zavatti, Patrizia (1999) Night Life in Europe and Recreative Drug Use, Valencia: Irefrea.

Calafat, Amador, Fernández, Cesáreo, Juan, Monserrat, Bellis, Mark A., Bohrn, Karl, Hakkarainen, Pekka, Kilfoyle-Carrington, Mary, Kokkevi, Anna, Maalsté, Nicole, Mendes, Fernando, Siamou, Ioanna, Simon, Joseph, Stocco, Paolo, and Zavatti, Patrizia (2001) Risk and Control in the Recreational Drug Culture - Sonar Project, Valencia: Irefrea.

Cancrini, Luigi (ed.) (1977) Esperienze di una ricerca sulle tossicomanie giovanili in Italia, Milan: Mondadori.

Colombo, Asher (1998) Etnografia di un'economia clandestina. Immigrati algerini a Milano, Bologna: Il Mulino.

Comune di Milano (2000) 'Linee di intervento per la città di Milano sull'abuso e dipendenze da sostanze stupefacenti. Anno 2000-2002. Proposta del 3 maggio 2000', Milan: Comune di Milano.

DCSA (Direzione Centrale per i Servizi Antidroga), Ministero dell'Interno (2002) Relazione Annuale 2001. Available online: http://www.ceis.it/focalpoint/.

EMCDDA (European Monitoring Centre on Drugs and Drug Addiction) (1998) Annual Report on the State of the Drugs Problem in the European Union. Luxembourg: Office for the Official Publications of the European Communities.

- (2001) Relazione annuale sull'evoluzione del fenomeno della droga nell'Unione Europea e in Norvegia. Luxembourg: Office for the Official Publications of the European Communities. Available online: http://www.annualreport.emcdda.eu.int. Accessed January 2003.

- (2002) Relazione annuale sull'evoluzione del fenomeno della droga nell'Unione Europea e in Norvegia. Luxembourg: Office for the Official Publications of the European Communities. Available online: http://www.annualreport.emcdda.eu.int. Accessed January 2003 
- (2003) Annual Report 2003: The State of the Drugs Problem in the European Union and Norway. Luxembourg: Office for the Official Publications of the European Communities. Available online: http://www.annualreport.emcdda.eu.int. Accessed June 2003.

EORG (European Opinion Research Group) (2002) Attitudes and Opinion of Young People in the European Union on Drugs. Report prepared by the European Opinion Research Group for the Directorate-General on Justice and Home Affairs, Eurobarometer 57.2, Special Eurobarometer 172. Brussels: European Commission.

Faccioli, Patrizia and Simoni, Simonetta (1984) 'Identità e droga nella società complessa', Dei delitti e delle pene 2(3): 578-93.

Gruppo Abele (2003) Synthetic Drugs Trafficking in Three European Cities: Major Trends and the Involvement of Organised Crime, Turin: Gipiangrafica.

Hobbs, Dick (1995) Bad Business: Professional Crime in Modern Britain, Oxford: Oxford University Press.

ISTAT (yearly) Statistiche Giudiziarie Penali, Rome: ISTAT.

— (2003) Popolazione Residente al $1^{\circ}$ Gennaio 2001 per età, sesso e stato civile. Available online: http://demo.istat.it. Accessed June 2003.

Jacobs, James B., Panarella, Christopher and Worthington, Jay (1994) Busting the Mob, New York: Oxford University Press.

Ministero del Lavoro e delle Politiche Sociali (2002) Relazione annuale al Parlamento sullo stato delle tossicodipendenze in Italia 2001. Available online: http://www. welfare.gov.it/aree+di+interesse/sociali/droghe $+\mathrm{e}+$ tossicodipendenze/documenti/default.htm. Accessed June 2003.

Ministero dell'Interno (2001) Relazione semestrale sull'attività svolta e $i$ risultati conseguiti dalla Direzione Investigativa Antimafia nel secondo semestre del 2000, Rome: Ministero dell'Interno. Available online: http://www.interno.it/dip_ps/dia/semestrali.htm. Accessed January 2003.

Ministero della Salute (2002) Rilevazione attività nel settore tossicodipendenze-Anno 2001. Available online: http://www.ceis.it/focalpoint/. Accessed January 2003.

OIDT (Osservatorio italiano per la verifica dell'andamento del fenomeno delle droghe e delle tossicodipendenze) (2002) The State of the Drug Problem in Italy (2001). Annual Report for the European Monitoring Centre for Drugs and Drug Addiction. Available online: http://www.ceis.it/focalpoint/. Accessed June 2003.

- (2003) Italy: Drug Situation 2001. Report to the EMCDDA by the Reitox National Focal Point. Available online: http://www.emcdda.eu.int/infopoint/publications/ national_reports.shtml>. Accessed June 2003.

Paoli, Letizia (2000a) Fratelli di mafia. Cosa Nostra e 'Ndrangheta, Bologna: Il Mulino.

- (2000b) Pilot Project to Describe and Analyse Local Drug Markets - First Phase Final Report: Illegal Drug Markets in Frankfurt and Milan, Lisbon: EMCDDA.

- (2002) 'The paradoxes of organised crime', Crime, Law, and Social Change 37(1): $51-97$.

- (2003) Mafia Brotherhoods: Organized Crime, Italian Style, New York: Oxford University Press.

- (2004) 'Italian organised crime: Mafia associations and criminal enterprises', Global Crime, forthcoming.

Parker, Howard, Aldridge, Judith and Measham, Fiona (1999) Illegal Leisure: The Normalization of Adolescent Recreational Drug Use, London: Routledge.

Piccone Stella, Simonetta (1999) Droghe e tossicodipendenza, Bologna: Il Mulino.

PrMI (Procura della Repubblica di Milano) (1997) Requisitoria del P. M. Maurizio Romanelli nella causa penale contro Agnifili + altri, Procedimento n. $16+19+20 / 94.6$ $+11+12+14 / 95$. 
— (2000) Verbali di interrogatorio di Pasquale Centore, Milan: Procura della Repubblica di Milano.

Reuter, Peter (1985) The Organization of Illegal Markets: An Economic Analysis, Washington, DC: National Institute of Justice.

Ruggiero,Vincenzo (1992) La roba. Economie e culture dell'eroina, Parma: Pratiche editrice. Rusconi, Marisa and Blumir, Guido (1972) La droga e il sistema, Milan: Feltrinelli.

TrMI (Tribunale di Milano), Corte d'Assise (1997) Sentenza nella causa penale a carico di Agil Fuat +132 , Procedimento n. 443/93, 11 June.

TrPA (Tribunale di Palermo), Ufficio Istruzione Processi Penali (1985) Ordinanza-sentenza di rinvio a giudizio nei confronti di Abbate Giovanni + 706, 8 November. 
Copyright of Journal of Modern Italian Studies is the property of Routledge, Ltd. and its content may not be copied or emailed to multiple sites or posted to a listserv without the copyright holder's express written permission. However, users may print, download, or email articles for individual use. 